\title{
Kernos
}

Revue internationale et pluridisciplinaire de religion grecque antique

$10 \mid 1997$

Varia

\section{JOURDAIN-ANNEQUIN, C. BONNET (éds), Héraclès, les femmes et le féminin}

\author{
Vinciane Pirenne-Delforge
}

URL : http://journals.openedition.org/kernos/682

DOI : $10.4000 /$ kernos.682

ISSN : 2034-7871

\section{Éditeur}

Centre international d'étude de la religion grecque antique

\section{Édition imprimée}

Date de publication : 1 janvier 1997

Pagination : 345-347

ISSN : 0776-3824

Référence électronique

Vinciane Pirenne-Delforge, "C. JouRdain-annequin, C. bonnet (éds), Héraclès, les femmes et le féminin ", Kernos [En ligne], 10 | 1997, mis en ligne le 12 avril 2011, consulté le 22 septembre 2020. URL : http:// journals.openedition.org/kernos/682 ; DOI : https://doi.org/10.4000/kernos.682 
La variété thématique fait le grand intérêt que ce recueil pour ceux qui étudient la religion et la mythologie classiques et pour ceux qu'intéressent leurs prolongements en Occident, singulièrement en Espagne.

Ángel Ruiz Pérez

(Université de Valladolid)

Colette Jourdain-Annequin, Corinne Bonnet (éds), II Rencontre Héracléenne. Héraclès, les femmes et le féminin. Actes du Colloque de Grenoble. Université des Sciences Sociales (Grenoble II), 22-23 octobre 1992, BruxellesRome, Brepols, 1996. 1 vol. $25,5 \times 19 \mathrm{~cm}, 291$ p. (Institut Historique Belge de Rome. Études de Pbilologie, d'Archéologie et d'Histoire Anciennes, 31). ISBN: 90-74461-12-3.

L'introduction de Nicole LORAUX au thème du colloque en montre à la fois l'importance et la richesse. Elle évoque en outre l'intensité de ces journées grenobloises, fertiles en discussions. C'est moins la féminité d'Héraclès - un sujet que N. LORAUX a elle-même étudié brillamment - que ses rencontres féminines, femmes et déesses, dans le mythe et dans le culte, auxquelles s'attachent les différentes études du volume. La présentation systématique qui suit espère leur rendre justice derrière la sécheresse de la synthèse toujours trop brève.

Bernard SERGENT (Ces demoiselles de Stymphale) propose une étourdissante comparaison gréco-irlandaise qui replace la quête des pommes des Hespérides, le combat contre les oiseaux de Stymphale et la guerre contre les Amazones dans l'éclairage du rapport d'Héraclès avec Artémis, Arès et Athéna. - Pierre BRulÉ (Héraclès et Augé. À propos des origines rituelles du mythe), parti de la frise de l'autel de Zeus à Pergame où Héraclès espionne Augé en canéphore au sein dénudé, tente d'expliquer cette nudité partielle par une étude attentive du mythe en toutes ses versions et de son arrière-plan rituel, fait de pannycbis, de procession, de chœur et de jeunes filles offertes au regard des hommes qui ne peuvent que constater leur maturité sexuelle. Didier PRALON (Héraclès-Iole), partant d'un schéma matrimonial proposé par G. Dumézil pour baliser le parcours héracléen, passe en revue les traditions principales autour des interventions de Iole et vérifie ainsi la description dumézilienne d'une héroïne passive, surtout intéressante par ce dont elle est l'enjeu. - Françoise LÉTOUBLON (Héraclès et les Thespiades) analyse d'un point de vue littéraire les trois passages qui évoquent l'épisode des Thespiades, ces 50 filles de Thespios auxquelles Héraclès s'unit successivement 50 jours de suite, ou même en une seule nuit : Apollodore (II, 65-66); Pausanias (IX, 27, 6-8); Diodore (IV, 29, 2-6). Le héros s'y situe à la veille de ses principaux exploits, en un épisode qui le fait, démesurément, devenir un homme. Cette prodigieuse fécondation expliquera aussi l'omniprésence d'H. en Béotie, autrement que par le mythe de sa naissance, ainsi que l'hellénisation du monde par ses descendants.

Stefan RITTER (Ercole e Onfale nell'arte romana dell'età tardo-repubblicana $e$ augustea) analyse les représentations d'Héraclès et d'Omphale dans la glyptique, la céramique arétine et dans la poésie romaines de la fin de la République et du début de l'Empire; elles montrent le héros dans sa vie privée, une image de la douceur de vivre et de la puissance de l'amour, à l'écart des vertus traditionnelles ou de toute déclaration d'intention. L'A. refuse donc les lectures « idéologiques » habituelles. - F. WulfF 
Alonso (L'Histoire d'Omphalè et d'Héraklès) aborde, dans une perspective anthropologique aux forts accents psychanalytiques, l'épisode du séjour d'Héraclès chez Omphale et les péripéties qui s'y déroulent. Elle montre avec finesse toutes les implications d'ordre hiérarchique, honorifique, sexuel qui caractérisent cette histoire où la complexité du héros est plus que jamais réaffirmée. - Corinne BONNET (Héraclès travesti) s'intéresse au contexte initiatique, progessivement oublié ou mal compris, auquel se rapportent les travestissements d'Héraclès qui comptait un péplos parmi les dons guerriers de sa panoplie héroïque. L'évolution historique explique sans doute «l'ambivalence de fond que ces apparitions d'Héraclès-femme révèlent », tout autant que ne le fait le caractère profondément paradoxal de ce personnage qui vit tout ce qui peut se vivre. - Paolo SCARPI (Héraclès. Trop de mets, trop de femmes) montre que, par ses excès, notamment alimentaires et sexuels, Héraclès demeure à l'écart de l'ordre civique, et même lorsqu'il établit la civilisation, il demeure en dehors de la vie civilisée. Monstre dans l'ordre de l'humain, Héraclès ne peut que devenir dieu. Son agrégation sera de l'ordre du divin et non de l'ordre du civique.

Françoise BADER (Héraklès, Ogmios et les Sirènes) part de l'Héraclès où Lucien affirme que les Celtes appellent Héraclès leur dieu de la poésie Ogmios, qu'ils représentent très vieux. En un parcours long et sinueux, c'est cette assimilation que l'A. entend expliquer, avec une abondance de rapprochements linguistiques et de comparaisons littéraires, philosophiques et mythologiques. Les Sirènes viennent en fin de parcours teinter de couleurs plus ou moins féminines cette réflexion difficile à saisir pour le non initié. - Lorenzo BraCcesI (Le fidanzate di Eracle) évoque les «fiancées d'Héraclès » en Occident; elles relèvent de la propagande, sicilienne d'une part, romaine d'autre part. La première, une jeune fille d'Hyperborée, donne naissance à Latinos, ancêtre des Latins, dans l'optique partisane de l'historiographie sicéliote antiromaine de Denys l'Ancien; cette tradition promeut l'existence d'une syngéneia " celto-hellénique » d'origine syracusaine. La deuxième, Keltiné fille de Bretannos, met au monde Keltos, l'éponyme des Celtes. Elle s'inscrit dans la propagande pro-romaine de la fin de la République, qui veut diviniser César en projetant l'image d'Héraclès sur ses conquêtes des confins. - Nicola Cusumano (Eracle e l'elemento femminile in Sicilia. Per un modello interpretativo delle forme di contatoo tra indigeni e colonizzatori nella Sicilia greca) offre une étude centrée sur la geste d'Héraclès en Sicile telle que la rapporte Diodore de Sicile; il propose, avec finesse et à propos, d'utiliser, pour analyser les relations entre Grecs et indigènes de Sicile, la grille de lecture des rapports " masculin-féminin » dans les poleis grecques, vus comme une tension permanente entre la séparation et le mélange. - Maurizio GIANGIULIo (Le béros fondateur et l'espace sacré de la déesse. Notes sur Héraclès et les sanctuaires d'Héra du Péloponnèse à la Grande Grèce) établit une brillante comparaison des circonstances de la fondation par Héraclès du temple d'Héra Lakinia à Crotone et de celui d'Héra Aigophagos à Sparte; il montre qu'à chaque fois, Héraclès, sous le patronage de la déesse, fonde ou refonde l'ordre civique par un ou plusieurs meurtres qui en sont les prémisses nécessaires.

Annie-France LAURENS (Héraclès et Hébé dans la céramique grecque ou les noces entre le ciel et la terre) étudie l'imagerie céramique grecque des Noces d'Hébé et d'Héraclès, et en montre la grande diversité. Les constantes en sont la mise en perspective du mariage humain dans trois de ses séquences rituelles (préparation des époux, cortège, accueil dans la maison) et l'immobilité bienheureuse que suggère 
l'intégration du héros parmi les dieux. L'union d'Hébé et d'Héraclès ne sera pas féconde car elle vise avant tout l'abolition des tensions, l'ataraxia incompatible avec la notion de descendance, de devenir, de lendemain. - Claudine LEDUC (Atbéna et Héraklès : une parenté botanique?), au départ de la coupe de Douris représentant Athéna versant une libation à Héraclès devant un olivier, nous propose une ingénieuse explication botanique des parentés du héros et de la déesse : Athéna à l'olivier-élaia, l'arbre féminin et vierge, d'une part, Héraclès à la massue en bois d'olivier-kotinos, mâle et sauvage, affirmant sa sexualité notamment dans le port de cette arme, d'autre part. Affaire à suivre, assurément. - Colette JOURDAIN-ANNEQUIN (Héraclès et les divinités féminines), entre le mythe panhellénique, qui voit surtout Héra et Athéna autour d'Héraclès, et les cultes et mythes épichoriques, où le côtoient Aphrodite, Artémis et les Deux Déesses, montre l'importance des cités dans la structuration de leur patrimoine mythique et cultuel local.

Vinciane PIRENNE-DELFORGE

(Université de Liège)

Simon Byl, Lambros Couloubaritsis (éds), Mythe et Philosophie dans les Nuées d'Aristophane, Bruxelles, Éditions Ousia, 1994. 1 vol. $14 \times 21 \mathrm{~cm}$, 253 p. (Ébauches). ISBN : 2-87060-043-7.

Outre un avant-propos et de brèves conclusions soulignant l'extraordinaire richesse des Nuées, l'ouvrage se compose de sept communications qui ont été présentées au Centre de philosophie ancienne de l'Université Libre de Bruxelles; elles sont autant de lectures différentes de la pièce, et plusieurs s'intéressent aux éléments religieux qu'elle véhicule. Dans son article intitulé « Les Mystères d'Éleusis dans les Nuées », S. BYL rassemble, en les complétant, les données de plusieurs études publiées depuis 1980 et qui tendent à montrer que l'initiation éleusinienne forme la toile de fond d'une grande partie de cette comédie, en dépit du fait que le nom de la cité attique n'y est jamais prononcé; les scholiastes antiques et médiévaux, à la différence des philologues modernes, avaient déjà, note-t-il, remarqué le fait. La démonstration, très convaincante, s'appuie sur plusieurs dizaines d'allusions détectées par l'auteur et commentées par lui avec une fine érudition. Aucune impiété n'est décelée envers ces Mystères auxquels Aristophane, conclut-il, était sans doute initié.

L. Couloubaritsis réfléchit pour sa part sur la portée de cette parodie, estimant que la comédie va plus loin et vise à porter en dérision le savoir sophistique ainsi que la légende liée aux Mystères éleusiniens dont se fait l'écho Hérodote (VIII, 65). M. MEULDER montre que la pièce était censée se dérouler le jour même où avait lieu l'initiation éleusisinienne, le 20 Boédromion; il vise aussi à établir que la conception de l'air qu'Aristophane emprunte à Diogène d'Apollonie aurait un caractère mystique qui le met en relation avec les rites initiatiques et que le rôle attribué au chœur des Nuées à la fin de la pièce rappelle celui des Erinyes eschiléennes. P.-J. DEHON, relevant l'abondance de références aux divinités traditionnelles, reconnaît dans la pièce un plaidoyer tendant à réhabiliter la religion ancestrale.

Les contributions de Fr. RONSMANS et de B. DECHARNEUX concernent respectivement les emprunts faits à Diogène d'Apollonie et le personnage de Socrate, notamment son caractère d'initié. 